\title{
Familial Guilt: Judgments of Collective Family Responsibility in the United States and South Korea
}

\author{
Junho Lee ${ }^{\mathrm{a}}$ \\ Keith J. Holyoak ${ }^{\mathrm{a}}$
}

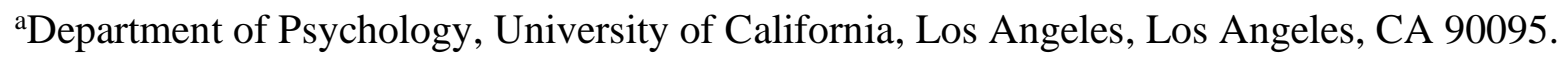

Running Head: Familial Guilt

Corresponding author:

Junho Lee

University of California, Los Angeles

E-mail: leejunho@ucla.edu

Declarations of interest: none 


\begin{abstract}
When a group member commits wrongdoing, people sometimes assign responsibility and blame not only to the wrongdoer but also to other members of the same group. We examined such assignment of collective responsibility in the context of exploitation of one family by another. Participants were recruited from an individualistic society (United States) and a more collectivistic society (South Korea) to assess differences in assignment of collective responsibility. Participants in both countries rated the degree to which an agent (grandson) should be held responsible for his grandfather's exploitation of a victimized family, while varying the closeness of familial connection. Participants' responsibility judgments showed sensitivity to whether the grandson received financial benefit from the wrongdoer and to the perceived closeness between the grandson and the wrongdoer. Korean participants imposed greater responsibility on the agent than did American participants. Implications for understanding the influence of social norms on moral judgments are discussed.
\end{abstract}

Keywords: collective responsibility; moral judgment; collectivism; cross-cultural difference; family relationship 


\section{Introduction}

In April 2007, the world was shaken by a horrific mass shooting incident at Virginia Polytechnic Institute and State University. The shooter, Seung-Hui Cho, was a permanent resident of the United States who had immigrated from South Korea when he was young. Members of Korean-American communities and Korean nationals were concerned with the fact that Cho was identified as a member of their own ethnic group. Koreans—including then-president Roh Moo-hyun—were quick to express grief and even guilt for what had happened to the victims (Veale, 2007). An elderly Korean interviewed by The New York Times summarized such sentiments clearly: "I and all of South Korea want to apologize to all Americans about what happened" (Choe \& Onishi, 2007).

Koreans are not unique in voluntarily taking such vicarious responsibility. Over several generations, some White Americans have expressed guilt for the enslavement and mistreatment of African Americans and indigenous peoples by early White Americans (Chudy, Piston, \& Shipper, 2019; Swim \& Miller, 1999; Iyer, Leach, \& Crosby, 2003). Postwar generations in Germany have been apologetic to Jews for the atrocities committed under the rule of the Nazi party (Wohl, Branscombe, \& Klar, 2006). In an ethnographic study that analyzed the electronic Human Relations Area Files (eHRAF; Curtin et al., 2020), indications of collective guilt were found in 45 out of 71 societies around the world. Jaspers (2009) distinguished between guilt based on one's own conduct and guilt based on one's identity, dubbing the latter "metaphysical guilt"; others have termed it "moral taint" (Silver, 2006; Uhlmann, Zhu, Pizarro, \& Bloom, 2012). Here we focus specifically on guilt related to actions by other people in (or closely connected to) one's own family, which we term familial guilt.

Familial guilt can be considered a special case of the distribution of collective responsibility to individual members of a group (Smiley, 2017; Radzik, 2001). The very idea of collective responsibility runs counter to traditional accounts of how responsibility ought to be imposed as formulated in Western philosophy (Smiley, 2017). Philosophers have postulated that, in a typical setting, to hold an individual 
responsible or blameworthy for a wrongdoing requires assuming that the individual has acted as a moral agent. That is, the individual must have acted freely rather than under coercion to cause harm, intended the action, and believed that their action was wrong (for a philosophical review see Talbert, 2019). Recent studies in moral psychology have confirmed that the mental states of the agent inferred by the reasonerespecially those pertaining to whether the agent had control over their action and harm-are indeed critical determinants of moral judgments of responsibility, wrongness, and blame (e.g., Alicke, 2000; Malle, Guglielmo, \& Monroe, 2014; Cushman, 2008; Lagnado \& Channon, 2008; Cushman \& Young, 2011; Greene et al., 2009; Giffin \& Lombrozo, 2018; Gerstenberg et al., 2018; Waldmann \& Dieterich, 2007; for reviews see Bartels, Bauman, Cushman, Pizarro, \& McGraw, 2015; Gugliemo, 2015).

However, recent cross-cultural studies in anthropology (Barrett et al., 2016) have challenged the universality of these fastidious conditions for assignment of responsibility and blame. Barrett and colleagues argued that the strong emphasis on mental states as determinants of moral violations is largely limited to Western, Educated, Industrialized, Rich, and Democratic (WEIRD) societies. They found that participants from eight small-scale traditional societies were less sensitive to the intention of the agent and more focused on the outcome of the action than were participants from Western societies when making moral judgments (also see Curtin et al., 2020).

The case of familial guilt takes a step further: moral responsibility is assigned not only to people who lack awareness or intent of the wrongdoing, but also to people who made no causal contribution to it. As the real-world examples discussed above illustrate, responsibility and blame are often assigned to, or willingly self-imposed by, people who merely share group affiliation with the wrongdoer (Ferguson \& Branscombe, 2014). On the other hand, in legal domain, blaming people based on their personal ties to a wrongdoer is typically dismissed as the fallacy of guilt by association. It remains controversial whether assigning responsibility and guilt based on group membership can sometimes be normative or justifiable (Radzik, 2001; Smiley, 2017; Silver, 2006). We performed a study to assess the propensity to provide 
financial restitution to descendants of victims harmed by one's own ancestor (a grandfather). Importantly, we tested the hypothesis that collectivistic social norms can lead people to assign more collective responsibility to others (Triandis, 2001). The U.S. and South Korea were chosen as useful examples of individualistic and collectivistic societies, respectively, based on many studies that investigated the 'EastWest' distinction. Previous literature (Bedford \& Hwang, 2003; Triandis \& Gelfand, 1998; Oyserman, Coon, \& Kemmelmeier, 2002; Henrich, Heine, \& Norenzayan, 2010; Graham, Meindl, Beall, Johnson, \& Zhang, 2016) have characterized Western societies influenced by the Judeo-Christian tradition as emphasizing individual rights over collective goals and duties. In comparison, East Asian societies influenced by Confucian tradition have been viewed as assigning greater importance to maintaining social order and harmony and fulfilling the duty to serve the common good of one's group or society. These general differences in norms suggest that South Koreans may have a greater propensity to offer recompense for bad acts committed by an ancestor, thereby settling the historical 'moral debt' and restoring intergroup harmony.

The present study adapted a paradigm introduced by Uhlmann et al. (2012), who gave participants scenarios that varied the nature of the link between an agent (tasked to make financial restitution to descendants of the victims) and their grandfather (the wrongdoer). This link was either biological or not (in the latter case, the agent's grandmother had divorced and remarried before he was born, and her second husband was the wrongdoer). Uhlmann et al. hypothesized and showed that people's intuitive belief in essentialism transfers the moral taint of the older wrongdoer to his descendant more strongly when they were connected through blood ties.

To examine the impact of a wider range of relations, the present study included two additional conditions involving family connection via adoption and a baseline where the wrongdoer and the agent were unrelated. We hypothesized that perceived "oneness" of the wrongdoer and the agent as members of a common group (entitativity; Campbell, 1958) would be highest for the biological condition, followed by 
the adoptive, remarriage, and no-relation conditions. Acceptance of collective responsibility was expected to increase with entitativity.

Orthogonally to the relationship conditions, we varied the presence and absence of a financial benefit the agent had received from the wrongdoer. Historical exploitation often results in advantages for the exploiter group and disadvantages for the victim group. Radzik (2001; Iyer et al., 2003) argued that the collective responsibility of members of the exploiter group to make reparations can derive from the advantages they inadvertently received. By using a factorial design, our study tests whether the effects of financial benefit and relationship on collective responsibility judgment can be distinguished. In addition, we tested the hypothesis that members of a collectivistic society (Koreans) as compared to members of an individualistic society (United States) may be more sensitive to the types of relations between the agent and the wrongdoer, or perhaps more generally accepting of collective responsibility to remedy a past injustice.

\section{Method}

\subsection{Participants}

Uhlmann et al. (2012, Study 1) reported that the effect size based on biological relatedness between grandfather and grandson on recommended restitution was Cohen's $d$ of 0.48 . Using G*Power, we calculated the sample size required to detect an effect of the same size in pairwise $t$-tests between four relationship conditions. For a minimum power of .80 and $\alpha$ of .05 in a two-tailed independent samples $t$ test, 70 participants were required in each group. Because we were interested in examining more finegrained variations in relatedness, we aimed for 80 in each of 16 groups. To show that a sufficient number

of participants were recruited for our ANOVAs, sensitivity analyses given the number of responses for each dependent variable are reported in the results section. The University of California, Los Angeles 
Institutional Review Board approved the procedures of the experiments in both the U.S. and Korea. Informed consent was obtained from all participants.

Amazon Mechanical Turk was used to recruit 649 American participants (283 females, 1 nonbinary gender; $M_{\text {age }}=37.8, S D_{\text {age }}=11.8 ; 18$ to 29 years $=27.6 \%, 30$ to 39 years $=37.4 \%, 40$ to 49 years $=17.6 \%, 50$ years or older $=17.4 \%$ ). Around 80 participants were assigned to each of eight betweensubject conditions for the American portion of the study. (See supplemental materials and data file uploaded in the online repository for exact numbers of participants in all groups.) When asked to selfidentify their ethnicity, $71 \%$ of American participants chose European/European American, $12 \%$ chose African American/Black, 9\% chose Asian/Asian American, 6\% chose Hispanic or Spanish origin, and 2\% chose other. American participants were paid $\$ 0.80$ for completing the experiment, which took around 4 minutes on average.

An additional 358 participants were recruited but excluded from analyses because they failed to correctly answer either of two comprehension checks (questions probing whether participants correctly remembered the two critical manipulations in each condition). These exclusions were mainly due to participants misremembering that the agent financially benefitted from the older wrongdoer when he did not, or that the two were members of the same family when they were not (control condition). (See supplementary materials for an analysis of exclusion rates and tentative explanations.)

After collecting data from American participants, we recruited 641 Korean participants (347 females; $M_{\text {age }}=36.7, S D_{\text {age }}=11.9 ; 18$ to 29 years $=35.1 \%, 30$ to 39 years $=34.9 \%, 40$ to 49 years $=$ $15.0 \%, 50$ years or older $=15.0 \%)$ from Hankook research's (https://www.hrc.co.kr/eng/) online survey panel. Quotas were used to roughly match the distribution of age between the American and Korean samples. Participants who failed the comprehension checks were automatically dropped during the experiment in the survey agency's internal system, and therefore all Korean participants included in our dataset passed the comprehension checks. When asked whether they had been exposed to a foreign culture 
long enough (longer than 1-2 years) that their personality or personal values had been influenced by that culture, $23 \%$ of Korean participants $(n=145)$ answered 'yes'. This response was collected for a secondary analysis of the effect of exposure to non-Korean culture on the dependent measures for Korean participants. Korean participants were compensated with points in Hankook research's online system, which were worth around $\$ 0.80$ and could be converted to currency. They took about 5 minutes on average to complete the experiment.

\subsection{Design, Materials and Procedure}

The experimental design was a 2 (culture: U.S./South Korea) $\times 4$ (wrongdoer's relation to agent: biological grandfather/grandfather in adoptive family/grandfather based on remarriage of agent's grandmother/no-relation) $\times 2$ (financial benefit: present/absent) between-subjects factorial design, with each participant reading just one scenario. The design thus included a total of 16 conditions. For brevity, we will refer to the four levels of the relationship variable as biological, adoptive, remarriage, and norelation.

The basic content and structure of the scenarios were adapted from Study 1 of Uhlmann et al. (2012) (see supplementary materials for the full set of materials). In the American version, all scenarios started by stating the relationship between Sam (wrongdoer), an owner of a small factory in New York, and Brian Johnson, the agent in the scenario. The Korean version was first translated from the English version by the first author and then back translated by another bilingual speaker to check for tone and content. In the Korean version of the experiment, the characters were given Korean names and the city was changed from New York to Seoul. The relationship information was presented at the beginning of the scenarios (unlike Uhlmann et al.'s vignettes, which placed it at the end) in order to enhance the impact of the relationship manipulation by allowing participants to bear that relationship in mind when reading the rest of the scenario. 
To assess whether our English and Korean materials were equivalent in meaning and content, we conducted additional validation by recruiting four validators. Two of them (bilinguals who were native Korean speakers) independently translated our English materials to Korean and Korean materials to English, respectively, and jointly compared the English and Korean materials we used in our experiment to find any discrepancy in meaning. The third validator (native English speaker) compared the newly translated English materials with the English materials we used in the experiment, and the fourth validator (native Korean speaker) did the same with the Korean materials. The four validators did not report a notable discrepancy in meaning and content between the English and Korean materials, except for the difference in interpretation of the second item in the covariate measurement scale (identity fusion with family; see supplementary materials). This item was excluded from all analyses.

In the no-relation conditions, the scenarios stated that young Brian had been told stories about Sam Miller, a factory owner around his grandfather's age. In the other conditions, how Brian was related to his grandfather Sam was described: either biologically, through adoption, or based on remarriage of Brian's grandmother. The scenarios then described Sam's wrongdoing in the past, which involved exploiting some of the poorest residents of New York as employees. The O’Neal family was the largest group of employees who were especially exploited. Sam threatened them with termination if they complained about their working conditions, even after the two youngest members of the family died while working at the factory. Next, in the scenario for the no-relation condition with financial benefit present, it was stated that Brian received a scholarship award that was founded by Sam, which made it possible for him to attend college. In the other relationship conditions with financial benefit present, the scenarios stated that Brian inherited some of his grandfather Sam's fortune when he was 20 years old, which made it possible for Brian to attend college. When the no-relation condition was coupled with financial benefit absent, there was no mention of a scholarship. In the other relationship conditions with financial benefit absent, the 
scenarios stated that Sam's fortune ran out before Brian was born, and Brian received no inheritance from him.

Then, all scenarios described Brian as currently a middle-aged lawyer who recently won the lottery. He decides to donate a portion of his winnings, $\$ 10,000$ (converted to South Korean wons of roughly equivalent value in the Korean version: 1,000 man-won) to charity, and considers two causes: the International Hungry Children's Fund, and the education of descendants of the O'Neal family who remain needy today. Participants were asked: “How should he distribute the money between the O'Neal children's education and the International Hungry Children's Fund?" In the American version of the experiment, participants used two scroll bars to indicate the amount of money to be allocated to each cause. In the Korean version, two blank slots were provided for participants to type in the amount of money to be donated to each cause. ${ }^{1}$ In both versions, participants could proceed to the next question only when the two responses summed to $\$ 10,000$. The amount of money allocated to the O'Neal children's education was the first dependent measurement.

On the next page, participants were asked: "How responsible do you think Brian should feel for what happened to the O'Neal family?" (5-point scale, 1: not at all responsible, 2: slightly responsible, 3: somewhat responsible, 4: very responsible, 5: fully responsible) This score was used as the second dependent measurement. In the American version of the experiment, this responsibility question was added to the survey in the middle of data collection. As a result, only 285 out of 649 American participants received the responsibility question, whereas all Korean participants received this question.

On the following page, two questions were asked as comprehension checks: "What is Sam's relation to Brian?" and "Did Brian financially benefit from Sam's fortune?" Next, we administered the verbal version of a measure of participants' identity fusion with their own family (Swann Jr., Jetten, Gómez, Whitehouse, \& Bastian, 2012). Our preliminary study $\left(n_{U S}=161, n_{\text {Korea }}=200\right)$ using an analogous experimental design and vertical collectivism scale (eight items; Singelis, Triandis, Bhawuk, 
\& Gelfand, 1995) as a potential mediator between culture and dependent measurements showed that the difference in vertical collectivism scores between American and Korean participants was not significant $(t(359)=1.62, p=.105)$. The score also did not significantly correlate with the amount of donation suggested by either American or Korean participants $(|r| s<.09, p \mathrm{~s}>.22)$. These results suggested that individuals' collectivism measured at a general level (rather than with respect to a specific ingroup) may not predict the assignment of responsibility in a specific situation. Therefore, in this experiment, participants' identity fusion with their family was measured as a potential mediator that is more directly related to our scenario involving family members. Identity fusion measure included seven items (one of these was excluded because of issue in translation), each rated on a 7-point scale (1: strongly disagree; 7: strongly agree). The scale assesses how much people align themselves with an affiliated group and experience "oneness". In the present study, we replaced the word "country" in Swann Jr. et al.'s questionnaire with "family". Finally, basic demographic information was collected.

\section{Results}

A 3-way full-factorial ANOVA was conducted to assess the influence of culture, relationship, and financial benefit (as categorical variables) on the amount of donation to the O'Neal children's education (see Figure 1). Sensitivity analysis using $\mathrm{G}^{*}$ Power $(n=1,290, \alpha=.05$, power $=.80)$ indicated that our ANOVA is sensitive enough to detect an effect as small as Cohen's $f=0.08\left(\eta_{p}^{2}=.006\right)$. Donation amounts reported by Korean samples were analyzed after conversion to U.S. dollars.

The main effects of all three categorical variables were significant. The main effect of culture ( $F(1$, $\left.1274)=84.5, p<.001, \eta_{p}^{2}=.063\right)$ reflected greater overall mean donations for Korean $(M=\$ 6,996,95 \%$ $\mathrm{CI}=[\$ 6,784, \$ 7208])$ as compared to American $(M=\$ 5,647,95 \% \mathrm{CI}=[\$ 5,436, \$ 5,858])$ participants. $^{2}$ The main effect of financial benefit $\left(F(1,1274)=16.9, p<.001, \eta_{p}^{2}=.013\right)$ reflected greater overall mean donations when financial benefit was present $(M=\$ 6,629,95 \% \mathrm{CI}=[\$ 6,415, \$ 6,843])$ rather than absent $(M=\$ 5,998,95 \% \mathrm{CI}=[\$ 5,780, \$ 6,217])$. 
The main effect of relationship $\left(F(3,1274)=9.2, p<001, \eta_{p}^{2}=.020\right)$ was investigated in further detail using pairwise $t$-tests between pairs of relationship conditions for the four levels of this factor, with Holm-Bonferroni correction (adjusted $p$-values are reported). Participants judged that the amount of donation to the O'Neal children's education should be greater in the biological condition $(M=\$ 6,875$, $95 \% \mathrm{CI}=[\$ 6,596, \$ 7,155])$ than in the remarriage condition $(M=\$ 6,069,95 \% \mathrm{CI}=[\$ 5,745, \$ 6,393]$; $\left.t(661)=3.70, p_{a d j}=.001, d=0.29\right)$ and no-relation condition $(M=\$ 5,859,95 \% \mathrm{CI}=[\$ 5,548, \$ 6,170]$; $\left.t(629)=4.78, p_{a d j}<.001, d=0.38\right)$, but not the adoptive condition $(M=\$ 6,412,95 \% \mathrm{CI}=[\$ 6,106, \$ 6,718]$; $\left.t(662)=2.19, p_{a d j}=.086\right)$. The average recommended donation tended to be higher in the adoptive condition than in the no-relation condition, although this difference was not significant after correction $\left(t(625)=2.48, p_{a d j}=.053\right)$. The other two pairwise comparisons were not significant $\left(p_{a d j \mathrm{~s}}>.26\right)$.
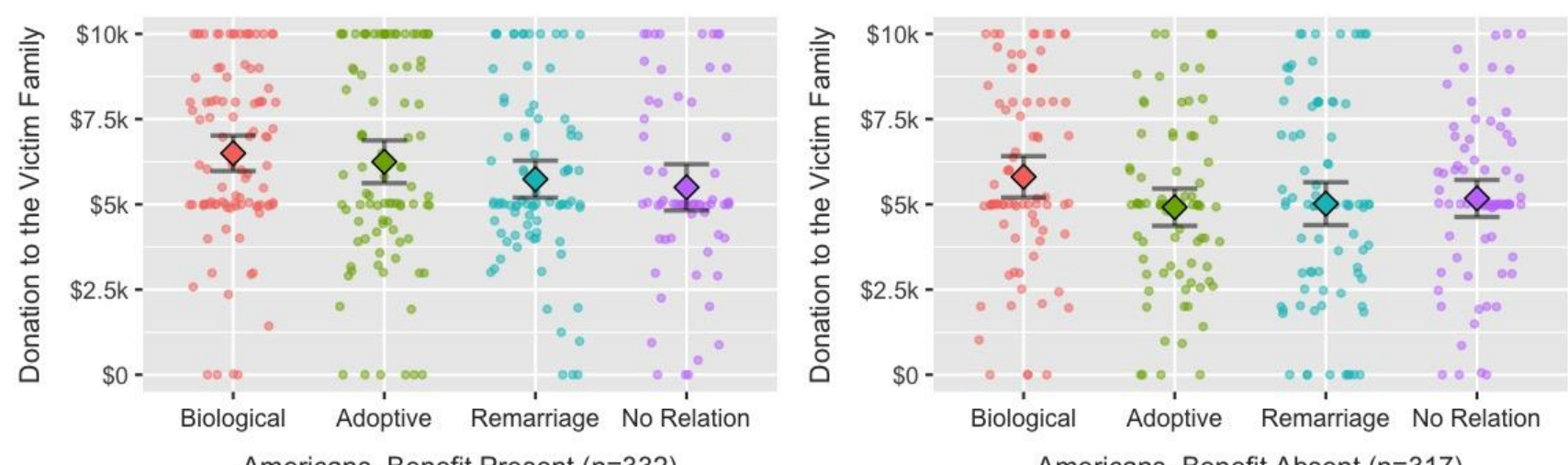

Americans, Benefit Present $(n=332)$
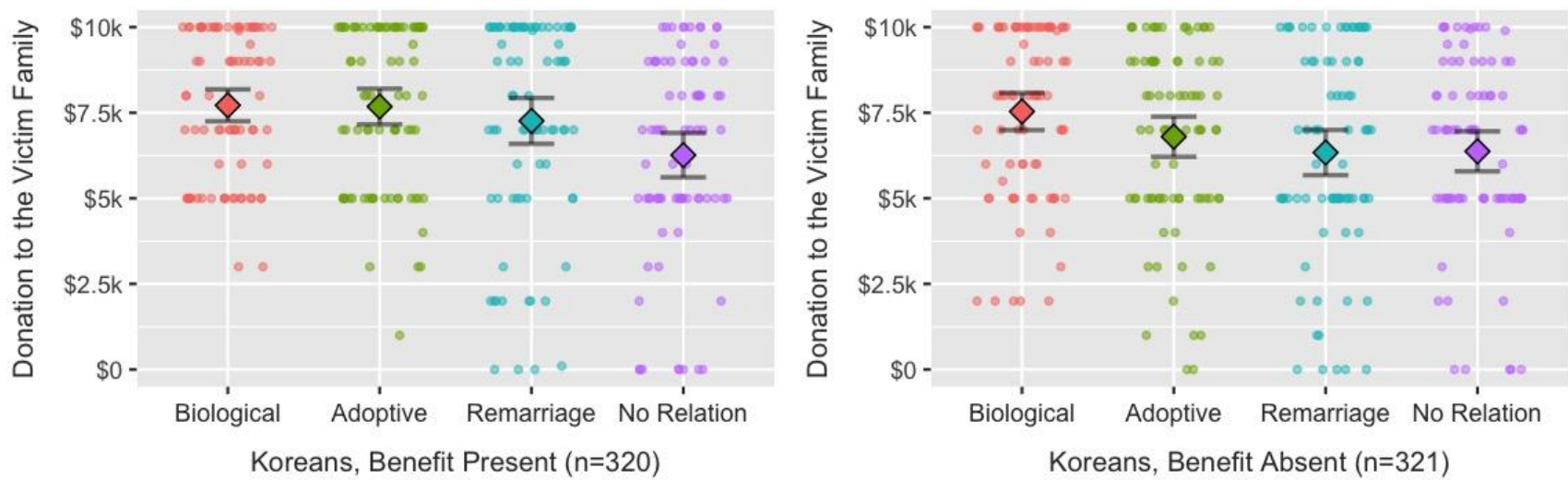

Koreans, Benefit Absent $(n=321)$ 
Figure 1. Amount of money donated to O'Neal children's education in each of the sixteen conditions Diamonds indicate group means. The dots show the distributions of responses across the range from $\$($ to $\$ 10,000$. Error bars indicate $95 \%$ confidence interval (assuming normal distribution).

None of the second- or third-order interaction effects were significant $(F \mathrm{~s}<2.06, p \mathrm{~s}>.103)$. We had anticipated that Korean participants might be more sensitive than Americans to variations in the family relationship between the agent and the grandfather. However, the 2-way interaction between culture and relationship was not significant $(F(3,1274)=0.87, p=.46)$. Regression models with dummy coding (rather than effect coding as in ANOVA) were used to test more specifically whether the effect of relationship significantly varied across cultures. In two regression models, the U.S. $\times$ biological $\times$ benefitpresent condition and U.S. $\times$ no-relation $\times$ benefit-present condition were respectively set as reference groups, and the benefit-absent dummy variable was entered as a first-order predictor. Six 2-way interaction terms between relationship manipulation and culture were tested, but none of them were significant ( $p$ s $>$.22). Hence, the relative differences between relationship conditions did not vary across cultures.

We also conducted separate one-way ANOVAs for American and Korean samples, using relationship to predict the amount of donations and collapsing across the levels of financial benefit. Relationship had a significant main effect in both samples $(F \mathrm{~s}>3.45, p \mathrm{~s}<.016)$. Pairwise $t$-tests with Holm-Bonferroni correction showed that American participants recommended greater amount of donations in the biological condition than in the remarriage $\left(p_{a d j}=.032\right)$ and no-relation $\left(p_{a d j}=.025\right)$ conditions. The other four differences were not significant ( $p_{a d j}>$.24). Similarly, Korean participants recommended greater amount of donations in the biological condition than in the remarriage $\left(p_{a d j}=.027\right)$ and no-relation $\left(p_{a d j}<.001\right)$ conditions. In addition, amount of donations was higher in the adoptive condition than in the no-relation condition $\left(p_{a d j}=.012\right)$. The other three differences were not significant ( $\left.p_{a d j \mathrm{~S}}>.42\right)$. 
To gauge the effect of culture conditional on the relationship conditions, we also conducted four independent $t$-tests comparing the suggested amount of donations from American and Korean samples in the four levels of relationship after collapsing across the levels of financial benefit. In all four conditions, Koreans suggested greater amount of donations than Americans ( $t \mathrm{~s}>3.17, p \mathrm{~s}<.002)$, and medium effect sizes were observed overall $\left(d_{\text {biological }}=0.58, d_{\text {adoptive }}=0.59, d_{\text {remarriage }}=0.49, d_{\text {no relation }}=0.37\right)$.

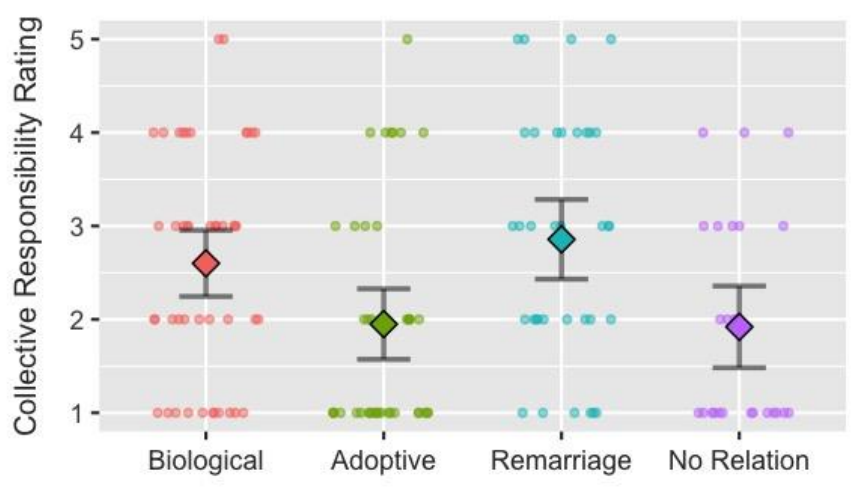

Americans, Benefit Present $(n=145)$

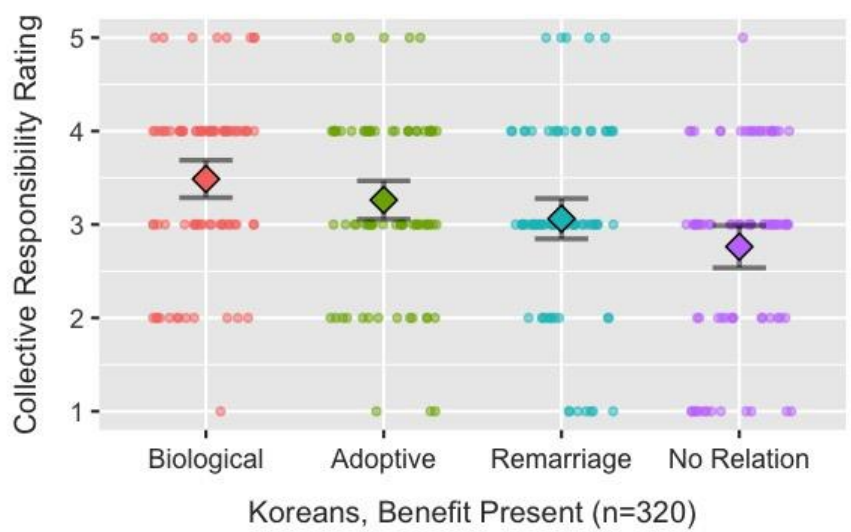

Figure 2. Participants' ratings that Brian should feel collective responsibility for what happened to the O’Neal family, in each of the sixteen conditions. Diamonds indicate group means. Distributions of data points across the range from 1 (not at all responsible) to 5 (fully responsible) are shown by the dots. Error bars indicate $95 \%$ confidence intervals (assuming normal distribution). 
Next, an analogous 3-way ANOVA was used to analyze predictors of the level of collective responsibility assigned to Brian (see Figure 2). As a reminder, 285 out of 649 American participants answered the collective responsibility rating question. Sensitivity analysis with $\mathrm{G}^{*}$ Power $(n=926, \alpha=.05$, power $=.80)$ indicated that our ANOVA is sensitive enough to detect an effect as small as Cohen's $f=$ $0.09\left(\eta_{p}^{2}=.008\right)$. As in the analysis of monetary donations, significant main effects of culture $(F(1,910)=$ $\left.142.8, p<001, \eta_{p}^{2}=.140\right)$, relationship $\left(F(3,910)=11.2, p<.001, \eta_{p}^{2}=.041\right)$, and financial benefit $(F(1$ $\left.910)=58.1, p<.001, \eta_{p}^{2}=.062\right)$ were found. As predicted, Koreans $(M=2.90,95 \% \mathrm{CI}=[2,82,2.98])$ assigned generally higher responsibility to the agent than did Americans $(M=2.03,95 \% \mathrm{CI}=[1.89,2.17])$. Across both cultures, collective responsibility score was higher when financial benefit was present $(M=$ $2.90,95 \% \mathrm{CI}=[2.80,3.01])$ than absent $(M=2.36,95 \% \mathrm{CI}=[2.25,2.47])$. In addition, the interaction between culture and relationship was significant $\left(F(3,910)=4.8, p=.003, \eta_{p}^{2}=.015\right)$. No other interaction effects were significant $(F \mathrm{~s}<2.58, p \mathrm{~s}>.052)$.

The significant interaction between culture and relationship was due to an unexpectedly high rating of responsibility in the remarriage condition among American participants but not among Korean participants (see Figure 2). Analogous to the follow-up tests we conducted for the amount of donations, two regression analyses were conducted using U.S. $\times$ biological $\times$ benefit-present and U.S. $\times$ no-relation $\times$ benefit-present conditions as reference groups, respectively. Among the U.S. participants, the responsibility ratings in the remarriage condition were significantly higher than in the no-relation condition $(b=0.60, t(917)=3.30, p=.001)$, and even higher than in the biological condition $(b=0.11$, $t(917)=0.63, p=.53)$. These high ratings in the remarriage condition relative to the two reference conditions significantly decreased in Korean participants (when no-relation was the reference group, $b_{\text {culture } \times \text { remarriage }}=-0.43, t(917)=-2.0, p=.046 ;$ when biological was the reference group, $\left.b_{\text {culture } \times \text { remarriage }}=-0.67, t(917)=-3.28 p=.001\right)$. Other interaction terms were not significant $(p \mathrm{~s}$ $>$.27). This deviation from the pattern may reflect the less reliable estimation of group means in the U.S. 
dataset due to smaller sample size. In any case, the linear models did not support our hypothesis that Koreans are more sensitive to relationship information than Americans (e.g., biological vs. no-relation difference is greater in Koreans than in Americans).

For completeness, we also conducted separate one-way ANOVAs for American and Korean samples where relationship predicted the responsibility ratings, after collapsing across the levels of financial benefit. Relationship had a significant main effect in both samples $(F \mathrm{~s}>3.87, p \mathrm{~s}<.009)$. Six pairwise $t$-tests with Holm-Bonferroni correction showed that American participants assigned less collective responsibility in the no-relation condition than in the biological $\left(p_{a d j}=.018\right)$ and remarriage $\left(p_{a d j}=.015\right)$ conditions. The other four differences were not significant $\left(p_{a d j} \mathrm{~s}>.24\right)$. Korean participants assigned greater collective responsibility in the biological condition than in the adoptive $\left(p_{\text {adj }}=.002\right)$, remarriage $\left(p_{a d j}<.001\right)$, and no-relation $\left(p_{a d j}<.001\right)$ conditions. They also assigned higher level of responsibility in the adoptive condition compared to the no-relation $\left(p_{a d j}=.018\right)$ condition. The other two differences were not significant $\left(p_{a d j} s>.32\right)$.

To assess the effect of culture in each relationship condition, we conducted four independent $t$ tests comparing the responsibility ratings of American and Korean samples in each of the four levels of relationship after collapsing across the levels of financial benefit. Koreans scored higher than Americans in all four conditions $(t \mathrm{~s}>3.11, p \mathrm{~s}<.003)$, and showed large effect sizes in most of the conditions $\left(d_{\text {biological }}=1.11, d_{\text {adoptive }}=0.95, d_{\text {remarriage }}=0.43, d_{\text {no relation }}=0.91\right)$. We also checked for any changes in the pattern of results after filtering out Koreans who self-reported a prolonged exposure to foreign culture $(23 \%)$. The statistical pattern remained the same for both ANOVAs after removing such participants.

The difference in identity fusion with family (average of six ratings; $\alpha=.93$ ) between American $(M=4.95,95 \% \mathrm{CI}=[4.84,5.05])$ and Korean $(M=5.21,95 \% \mathrm{CI}=[5.12,5.31])$ participants was significant $(t(1,288)=3.61, p<.001, d=0.20)$. The identity fusion score was added to the two 3 -way 
ANOVAs reported above as an additional first-order predictor. For these analyses, no-relation conditions

(137 Americans and 160 Koreans) were excluded because identity fusion with family was expected to covary with the dependent measurements only when the scenario described the wrongdoer and the agent as members of the same family. Of the 285 American participants who answered the collective responsibility question, 57 were in the no-relation condition and were excluded. Results showed that over and above the significant effects of the three predictors already tested, the identity fusion score had a small effect on collective responsibility ratings $(b=0.10, t(696)=3.23, p=.001)$, but not on the amount of donation $(b=-\$ 12.52, t(980)=-0.19, p=.85)$.

We conducted mediation analyses using PROCESS macro version 3.0 for SPSS (Hayes, 2018). Pre-defined model 4 in PROCESS was used. Three dummy variables coding the levels of independent variables (indicating adoptive, remarriage, and benefit-present conditions, respectively) were entered as covariates for predicting the mediator (identity fusion score) and the dependent measurements. Indirect effects were estimated through bootstrapping $(n=20,000)$. The direct effect of culture on the suggested amount of donations was significant $(b=\$ 1,517, t(987)=8.84, p<.001,95 \% \mathrm{CI}=[\$ 1,180, \$ 1,854])$, while the indirect effect through identity fusion score was not $(b=-\$ 3.5,95 \% \mathrm{CI}=[-\$ 43.3, \$ 33.2])$. Similarly, when predicting the collective responsibility rating, the direct effect of culture $(b=0.89, t(703)$ $=10.43, p<.001,95 \% \mathrm{CI}=[0.72,1.06])$ was significant but the indirect effect through identity fusion score $(b=0.01,95 \% \mathrm{CI}=[-0.003,0.041])$ was not. Thus, our data did not support the hypothesis that participants' identification with their family mediates the influence of culture on collective moral judgments.

\section{Discussion}

Assignment of collective responsibility based on group membership deviates from the traditional moral norms supported as philosophical principles within the individualistic Western societies (Smiley, 2017; Talbert, 2019). Nevertheless, laypeople across cultures seem to take group membership into account 
when making moral judgments. The present study explored the impacts of culture, financial benefit, and closeness of family relationship on willingness to pay to remedy a wrong perpetrated by a family member in an earlier generation. We found that for both American and South Korean participants, judgments of collective responsibility were greater when the agent had received a financial benefit traceable to the wrongdoer. Participants also demonstrated sensitivity to the type of relation between the wrongdoer and the agent. A small but consistent trend was observed for closer family relationships (higher entitativity) to result in greater assignment of collective responsibility.

Culture was a strong predictor of both donations to descendants of victims and judgments of collective responsibility. The two groups were very similar with respect to the impact of both familial relationship and financial benefit, but Korean participants showed a greater imposition of collective responsibility across all conditions, even when the agent was unrelated to the wrongdoer and had not received a financial benefit traceable to the wrongdoing.

By extending Uhlmann et al. (2012), our results demonstrate an intriguing exception to the connection between causality and judgment of responsibility. Psychological theories of morality have postulated that causal relation between an agent's behavior and harm is critical for an observer to assign blame and moral responsibility to the agent (e.g., Malle, Guglielmo, \& Monroe, 2014; Cushman, 2008; Cushman \& Young, 2011; Zultan, Gerstenberg, \& Lagnado, 2012; Waldmann \& Dieterich, 2007; Greene et al., 2009). Therefore, the influence of non-causal factors (group identity, moral obligation, social norms, emotions; Malle, Guglielmo, \& Monroe, 2014; Ditto, Pizarro, \& Tannenbaum, 2009; Holyoak \& Powell, 2016) remains to be incorporated into rational computational models of moral judgments (e.g., Gerstenberg et al., 2018). Although South Koreans scored higher than Americans on a measure of identity fusion with family (Swann Jr. et al., 2012), this variable had a weak relationship to collective responsibility judgments. It is possible that people use different heuristics for making moral judgments in first-person versus third-person perspectives. Our scenarios dealt with the latter case, which may lead participants to 
rely more on cultural norms about how moral responsibilities should be assigned to individuals and groups. In contrast, participants' identity fusion with their own family may have significantly predicted the responsibility judgments if the scenarios were written in first-person perspective. Future studies should explore the underlying mechanisms that lead to within- and between-culture differences in group-based moral judgments. For example, variability in participants' appraisal of the situation (e.g., perceived entitativity between the wrongdoer and the agent) may better predict their responsibility assignments than do individual differences in their personal relationship with their family.

How should this cultural difference be interpreted? Collectivistic societies may tend to perceive a collective duty to remedy harms done to (and/or by) group members in a relatively unconditional manner. Greater attention to the duty and responsibility of individuals to other group members (Henrich, Heine, \& Norenzayan, 2010; Gold, Colman, \& Pulford, 2014) may have contributed to the higher scores observed for Korean participants. Even in the no-relation condition, communal Korean participants may have perceived the agent and the wrongdoer as fellow citizens of a society with high entitativity and assigned greater collective responsibility than the American participants did.

However, researchers have warned against overgeneralization of findings from studies on crosscultural differences. Our study included samples from only two countries, which may not be representative of individualistic versus collectivistic cultures. Moreover, the impact of culture on real-world judgments is likely to interact with particular types of social situations (e.g., people interact differently with coworkers, friends, and strangers; Chen \& West, 2008; Oyserman et al., 2002). Chen and West (2008) and Vignoles et al. (2016) have argued that the dimension of individualism/collectivism should be decomposed into multiple subdimensions, and that the global distinction is not a reliable predictor of people's behavior. Hence, we refrain from making strong claims about broad cultural differences between individualistic and collectivistic societies. Instead, our findings should be viewed as evidence that social and cultural norms can shape people's moral judgments in significantly different ways. 
A particularly potent social influence impacting people's everyday moral reasoning may be historical group dynamics, which has received less attention in moral psychology (but see Brown, González, Zagefka, Manzi, \& Čehajić, 2008; Doosje, Branscombe, Spears, \& Manstead, 1998). Historically, intergroup conflicts have produced cruelty (e.g., massacres) and exploitation of one group by another (e.g., slavery, colonization). Such events then shape one group's collective emotions (e.g., guilt, indignation) and attitudes toward the other. With the rapid increase in ethnic and cultural diversity in modern societies, conflicts between groups based on historically derived beliefs, values, and norms may become more frequent (Putnam, 2007; Kaplan, 2018). Future work in moral psychology should examine how people apply concepts such as responsibility, guilt, and reparation to realistic situations involving intergroup relations.

It will be interesting to investigate how our findings extend to more consequential decisions in various settings. In the U.S., for example, would individual difference in collectivism predict support for policies related to reparations for Native and African Americans, when other demographic variables are controlled for? In legal cases, would jurors with high collectivism scores tend to (perhaps incorrectly) assign collective responsibility based on group membership? Because collective responsibility has an intuitive appeal to many, it may be already pervading our moral decisions without our awareness.

\section{Open Practices Statement}

The experiment reported in this article was not preregistered. The de-identified data and materials have been made available on the Open Sciences Framework repository (https://osf.io/ubj9h/).

\section{Acknowledgements}

This research was supported by NSF Grant XXX. We thank Barbara Spellman for helpful comments and Chaewon Michelle Bak for help in translation of the materials. Correspondence concerning this article should be addressed to Junho Lee (leejunho@ucla.edu). 


\section{Footnotes}

1. Due to technical difficulty, scroll bars could not be implemented in the Korean version. A partial replication of the study with American participants showed that response format did not have any significant effect on the pattern of results (for details see supplementary materials).

2. All confidence intervals reported in this paper assume normal distributions, as the large sample sizes make the statistics robust to violations of normality. The same statistical pattern was obtained using the Aligned Rank Transformation ANOVA (Wobbrock, Findlater, Gergle, \& Higgins, 2011), a nonparametric test analogous to a factorial ANOVA implemented in R package ARTool (see SOM).

\section{References}

Alicke, M. D. (2000). Culpable control and the psychology of blame. Psychological Bulletin, 126(4), 556-574. https://doi.org/10.1037/0033-2909.126.4.556.

Bartels, D. M., Bauman, C. W., Cushman, F. A., Pizarro, D. A., \& McGraw, A. P. (2015). Moral judgment and decision making. In G. Keren \& G. Wu (Eds.), Wiley Blackwell handbook of judgment and decision making. Chichester, UK: Wiley.

Barrett, H. C., Bolyanatz, A., Crittenden, A. N., Fessler, D. M. T., Fitzpatrick, S., Gurven, M., Henrich, J., Kanovsky, M., Kushnick, G., Pisor, A., Scelza, B. A., Stich, S., von Rueden, C., Zhao, W. \& Laurence, S. (2016). Small-scale societies exhibit fundamental variation in the role of intentions in moral judgment. Proceedings of the National Academy of Sciences, USA, 113(17), 4688-4693. https://doi.org/10.1073/pnas.1522070113.

Bedford, O., \& Hwang, K. K. (2003). Guilt and shame in Chinese culture: A cross-cultural framework from the perspective of morality and identity. Journal for the Theory of Social Behaviour, 33(2), 127-144. https://doi.org/10.1111/1468-5914.00210. 
Brown, R., González, R., Zagefka, H., Manzi, J., \& Čehajić, S. (2008). Nuestra culpa: Collective guilt and shame as predictors of reparation for historical wrongdoing. Journal of Personality and Social Psychology, 94(1), 75-90. https://doi.org/10.1037/0022-3514.94.1.75.

Campbell, D. T. (1958). Common fate, similarity, and other indices of the status of aggregates of persons as social entities. Behavioral Science, 3, 14-25.

Choe, S.-H. \& Onishi, N. (2007, April 18). South Koreans react to shooting in Virginia. New York Times. Retrieved August 24, 2020 from https://www.nytimes.com/2007/04/18/world/asia/18cndkorea.html/.

Chudy, J., Piston, S., \& Shipper, J. (2019). Guilt by association: White collective guilt in American politics. Journal of Politics, 81(3), 968-981. http://dx.doi.org/10.1086/703207.

Curtin, C. M., Barrett, H. C., Bolyanatz, A., Crittenden, A. N., Fessler, D. M. T., Fitzpatrick, S., Gurven, M., Kanovsky, M., Kushnick, G., Laurence, S., Pisor, A., Scelza, B. A., Stich, S., von Rueden, C., \& Henrich, J. (2020). Kinship intensity and the use of mental states in moral judgment across societies. Evolution and Human Behavior, 41(5), 415-429. https://doi.org/10.1016/j.evolhumbehav.2020.07.002.

Cushman, F. (2008). Crime and punishment: Distinguishing the roles of causal and intentional analyses in moral judgment. Cognition, 108(2), 353-380. https://doi.org/10.1016/j.cognition.2008.03.006.

Cushman, F., \& Young, L. (2011). Patterns of moral judgment derive from nonmoral psychological representations. Cognitive Science, 35(6), 1052-1075. https://doi.org/10.1111/j.1551$\underline{6709.2010 .01167 . x}$.

Ditto, P. H., Pizarro, D. A., \& Tannenbaum, D. (2009). Motivated moral reasoning. In B. H. Ross (Series Ed.) \& D. M. Bartels, C. W. Bauman, L. J. Skitka, \& D. L. Medin (Eds.), Psychology of learning and motivation, Vol. 50: Moral judgment and decision making (pp. 307-338). San Diego, CA: Academic Press. https://doi.org/10.1016/s0079-7421(08)00410-6. 
Doosje, B., Branscombe, N. R., Spears, R., \& Manstead, A. S. (1998). Guilty by association: When one's group has a negative history. Journal of Personality and Social Psychology, 75(4), 872-886. https://doi.org/10.1037/0022-3514.75.4.872.

Ferguson, M. A., \& Branscombe, N. R. (2014). The social psychology of collective guilt. In C. von Scheve \& M. Salmela (Eds.), Collective emotions: Perspectives from psychology, philosophy, and sociology. UK: Oxford University Press.

Gerstenberg, T., Ullman, T. D., Nagel, J., Kleiman-Weiner, M., Lagnado, D. A., \& Tenenbaum, J. B. (2018). Lucky or clever? From expectations to responsibility judgments. Cognition, 177, 122-141. https://doi.org/10.1016/j.cognition.2018.03.019.

Graham, J., Meindl, P., Beall, E., Johnson, K. M., \& Zhang, L. (2016). Cultural differences in moral judgment and behavior, across and within societies. Current Opinion in Psychology, 8, 125-130. https://doi.org/10.1016/j.copsyc.2015.09.007.

Greene, J. D., Cushman, F. A., Stewart, L. E., Lowenberg, K., Nystrom, L. E., \& Cohen, J. D. (2009). Pushing moral buttons: The interaction between personal force and intention in moral judgment. Cognition, 111(3), 364-371. https://doi.org/10.1016/j.cognition.2009.02.001.

Gold, N., Colman, A., \& Pulford, B. (2014). Cultural differences in responses to real-life and hypothetical trolley problems. Judgment and Decision Making, 9(1), 65-76.

Guglielmo, S. (2015). Moral judgment as information processing: An integrative review. Frontiers in Psychology, 6, 1637. https://doi.org/10.3389/fpsyg.2015.01637.

Hayes, A. F. (2018). Partial, conditional, and moderated moderated mediation: Quantification, inference, and interpretation. Communication monographs, 85(1), 4-40. https://doi.org/10.1080/03637751.2017.1352100.

Henrich, J., Heine, S. J., \& Norenzayan, A. (2010). The weirdest people in the world?. Behavioral and brain sciences, 33(2-3), 61-83. https://doi.org/10.1017/S0140525X0999152X. 
Holyoak, K. J., \& Powell, D. (2016). Deontological coherence: A framework for commonsense moral reasoning. Psychological Bulletin, 142(11), 1179-1203. https://doi.org/10.1037/bul0000075.

Iyer, A., Leach, C. W., \& Crosby, F. J. (2003). White guilt and racial compensation: The benefits and limits of self-focus. Personality and Social Psychology Bulletin, 29(1), 117-129. https://doi.org/10.1177/0146167202238377.

Jaspers, K. (2009). The question of German guilt. New York: Fordham University Press.

Kaplan, S. D. (2018). Human rights in thick and thin societies: Universality without uniformity. Cambridge, UK: Cambridge University Press.

Lagnado, D. A., \& Channon, S. (2008). Judgments of cause and blame: The effects of intentionality and foreseeability. Cognition, 108(3), 754-770. https://doi.org/10.1016/j.cognition.2008.06.009.

Malle, B. F., Guglielmo, S., \& Monroe, A. E. (2014). A theory of blame. Psychological Inquiry, 25(2), 147-186. https://doi.org/10.1080/1047840X.2014.877340.

Oyserman, D., Coon, H. M., \& Kemmelmeier, M. (2002). Rethinking individualism and collectivism: evaluation of theoretical assumptions and meta-analyses. Psychological bulletin, 128(1), 3. https://doi.org/10.1037/0033-2909.128.1.3.

Radzik, L. (2001). Collective responsibility and duties to respond. Social Theory and Practice, 27(3), 455-471. https://doi.org/10.5840/soctheorpract20012735.

Silver, D. (2006). Collective responsibility, corporate responsibility and moral taint. Midwest Studies in Philosophy, 30, 269-278. https://doi.org/10.1111/j.1475-4975.2006.00139.x.

Singelis, T. M., Triandis, H. C., Bhawuk, D. P., \& Gelfand, M. J. (1995). Horizontal and vertical dimensions of individualism and collectivism: A theoretical and measurement refinement. Crosscultural research, 29(3), 240-275. https://doi.org/10.1177/106939719502900302. 
Smiley, M. (2017). Collective responsibility. In E. N. Zalta (Ed.), Stanford encyclopedia of philosophy (Summer 2017 edition). Retrieved August 24, 2020 from https://plato.stanford.edu/archives/sum2017/entries/collective-responsibility/.

Swim, J. K., \& Miller, D. L. (1999). White guilt: Its antecedents and consequences for attitudes toward affirmative action. Personality and Social Psychology Bulletin, 25(4), 500-514. https://doi.org/10.1177/0146167299025004008.

Talbert, M. (2019). Moral responsibility. In E. N. Zalta (Ed.), Stanford encyclopedia of philosophy (Winter 2019 edition). Retrieved August 24, 2020 from https://plato.stanford.edu/archives/win2019/entries/moral-responsibility/.

Triandis, H. C. (2001). Individualism-collectivism and personality. Journal of Personality, 69(6), 907924. https://doi.org/10.1111/1467-6494.696169.

Triandis, H. C., \& Gelfand, M. J. (1998). Converging measurement of horizontal and vertical individualism and collectivism. Journal of Personality and Social Psychology, 74(1), 118-128. https://doi.org/10.1037/0022-3514.74.1.118.

Uhlmann, E. L., Zhu, L. L., Pizarro, D. A., \& Bloom, P. (2012). Blood is thicker: Moral spillover effects based on kinship. Cognition, 124(2), 239-243. https://doi.org/10.1016/j.cognition.2012.04.010. Veale, J. (2007, April 18). South Korea's collective guilt. Time. Retrieved August 24, 2020 from http://content.time.com/time/nation/article/0,8599,1611964,00.html.

Vignoles, V. L., Owe, E., Becker, M., Smith, P. B., Easterbrook, M. J., Brown, R., González, R., Didlier, N., Carrasco, D., Cadena, M. P., Lay, S., Schwartz, S. J., Des Rosiers, S. E., Villamar, J. A., Gavreliuc, A., Zinkeng, M., Kreuzbauer, R., Baguma, P. Martin, M., ..., Brambilla, M. (2016). Beyond the 'East-West' dichotomy: Global variation in cultural models of selfhood. Journal of Experimental Psychology: General, 145(8), 966. https://doi.org/10.1037/xge0000175. 
Waldmann, M. R., \& Dieterich, J. H. (2007). Throwing a bomb on a person versus throwing a person on a bomb: Intervention myopia in moral intuitions. Psychological Science, 18(3), 247-253. https://doi.org/10.1111/j.1467-9280.2007.01884.x.

Wobbrock, J.O., Findlater, L., Gergle, D., \& Higgins, J.J. (2011, May). The aligned rank transform for nonparametric factorial analyses using only ANOVA procedures. In Proceedings of the SIGCHI Conference on Human Factors in Computing Systems (pp. 143-146). New York: ACM. https://doi.org/10.1145/1978942.1978963.

Wohl, M. J., Branscombe, N. R., \& Klar, Y. (2006). Collective guilt: Emotional reactions when one's group has done wrong or been wronged. European Review of Social Psychology, 17(1), 1-37. https://doi.org/10.1080/10463280600574815.

Zultan, R., Gerstenberg, T., \& Lagnado, D.A. (2012). Finding fault: causality and counterfactuals in group attributions. Cognition, 125(3), 429 - 440. https://doi.org/10.1016/j.cognition.2012.07.014. 